\title{
Research Trends of Thermally Activated Delayed Fluorescence Materials for Organic Light-Emitting Diodes
}

\author{
Ju Young Lee ${ }^{\dagger}$ \\ Department of Information Display, Kyung Hee University, Seoul
}

\section{OLED용 지연형광 소재의 연구 동향}

\author{
이주영 ${ }^{\dagger}$ \\ 경희대학교 정보디스플레이학과
}

(Received August 25, 2019; Accepted September 10, 2019)

\begin{abstract}
s
The development of highly efficient thermally activated delayed fluorescence (TADF) materials is an active area of recent research in organic light emitting diodes (OLEDs) since the first report by Chihaya Adachi in 2011. Traditional fluorescent materials can harvest only singlet excitons, leading to the theoretically highest external quantum efficiency (EQE) of $5 \%$ with considering about $20 \%$ light out-coupling efficiency in the device. On the other hand, TADF materials can harvest both singlet and triplet excitons through reverse intersystem crossing (RISC) from triplet to singlet excited states. It could provide $100 \%$ internal quantum efficiencies (IQE), resulting in comparable high EQE to traditional rare-metal complexes (phosphorescent materials). Thanks to a lot of efforts in this field, many highly efficient TADF materials have been developed. This review focused on recent molecular design concept and optoelectronic properties of TADF materials for high efficiency and long lifetime OLED application.
\end{abstract}

Keywords: TADF, OLED

\section{1. 배경}

OLED 기술은 1987년 Tang과 VanSlyke에 의해 최초 로 개발된 이후 많은 발전을 이루어 현재는 모바일 및 TV 에 상용화되었다. $\mathrm{OLED}$ 는 기존의 $\mathrm{LCD}$ 와 달리 자발광이
라는 특징 때문에 백라이트가 필요 없고 시인성이 좋으며 응답속도가 빠르고 시야각이 넓은 장점을 지닌다. 또한 고체 상태로 제작되므로 플렉시블 디스플레이로 제작이 용이한 장점을 가지고 있어 차세대 디스플레이로 주목을 받고 있다. 그러나 발광 소재의 스펙트럼과 효율, 안정성 

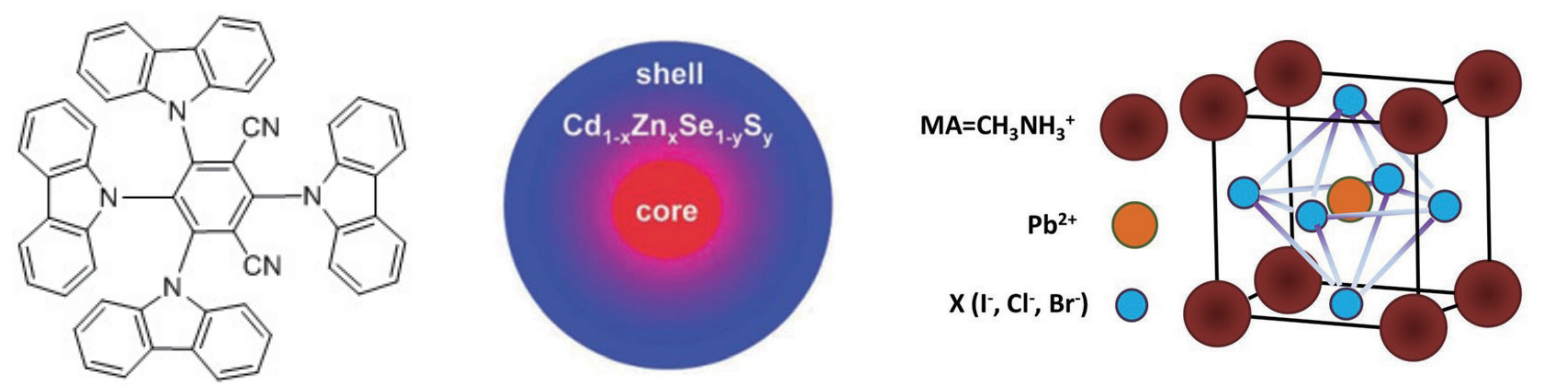

Fig. 1. OLED용 지연형광 소재, 양자점 및 페로브스카이트 양자점 소재의 구조.,2)

에 의해 결정되는 최대 밝기 및 색 재현율은 무기물 발광 소재를 쓰는 LCD가 유기물 발광소재를 사용하는 OLED 보다 더 우수하다. 이러한 OLED 발광소재의 특성을 개 선하기 위해 지연형광 소재, 양자점(QD: quantum dots), 페로브스카이트 (Perovskite) 양자점 등 다양한 소재 연구가 진행되고 있다.

현재 OLED에서 적색과 녹색 발광 소재는 효율 및 수 명이 뛰어난 인광 소재를 사용하는 반면, 청색은 효율이 낮은 형광 소재를 사용하기 때문에 전력 소모가 크다. 이 를 극복하기 위해 최근 열 활성 지연형광 (thermally activated delayed fluorescence, TADF) 소재가 활발 히 연구되고 있다. 양자점은 나노 크기의 반도체 입자로 발광 색상은 입자의 직경에 따라 다르다. 현재 양자점은 QD-LCD TV에서 컬러필터처럼 사용되고 있어 LCD와 같은 원리를 이용하므로 차세대 디스플레이에 적용하기 어렵다. 따라서 양자점을 $\mathrm{OLED}$ 의 발광층에 도입한
QLED가 활발히 연구되고 있다. 현재 카드뮴 계열 QLED 의 효율은 확보됐고, 청색을 제외하면 수명도 확보됐다. 하지만 카드뮴 계열 양자점은 인체에 유해해 최근에는 비 카드뮴 계열 QLED가 활발히 연구됐다. 하지만 효율과 수명 모두 크게 떨어져 이를 충족할 수 있는 소재 및 소자 개발이 필요한 상황이다. 페로브스카이트 양자점은 기존 양자점과 다르게 코어(core)를 감싸고 있는 껍질(shell) 이 없어도 높은 발광효율 및 색 순도를 나타낸다. 그러나 이 소재는 이온결합으로 이뤄진 결정이므로 쉽게 분해될 수 있어 기존의 양자점 관련 공정을 활용하기 어렵다. 더 구나 아직 표면 리간드 처리공정이 확실히 개발되지 않아 페로브스카이트 양자점 소재 최적화와 소자 응용에 어려 움이 있다. 하지만 이 분야는 아직 연구 초기 단계이기 때 문에 발전 가능성은 크다. 본 글에서는 이들 발광 소재 중 최근에 활발히 연구가 진행된 지연형광 유기소재와 개발 현황을 소개하고자 한다.
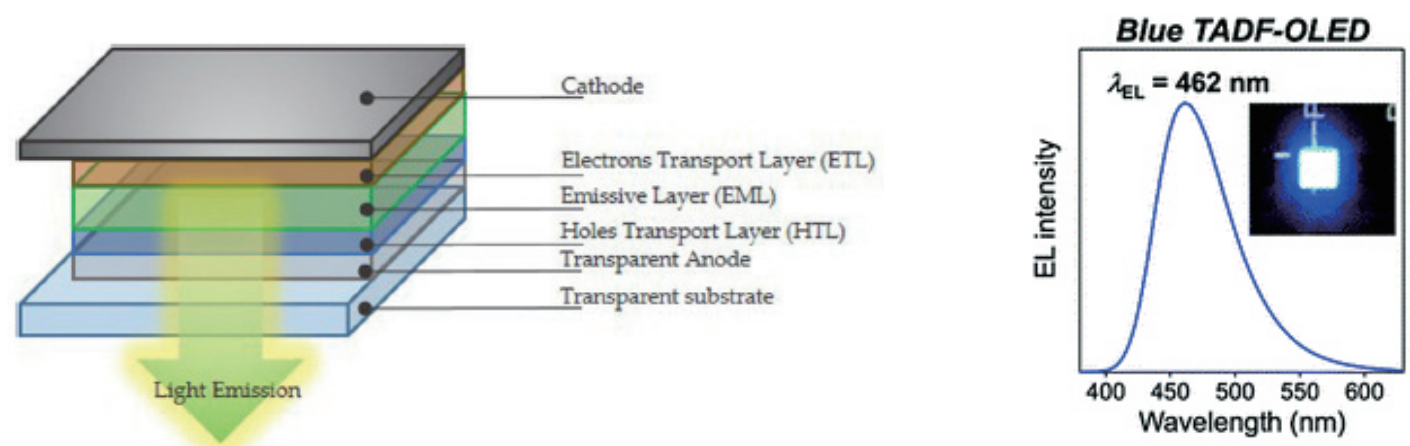

Fig. 2. 일반적인 OLED 소자의 구조 및 청색 TADF 소재를 사용한 소자.4) 


\section{2. 본론}

\subsection{OLED 발광 메커니즘}

$\mathrm{OLED}$ 는 전류구동 방식의 발광 소자로서, 전자와 정공 이 결합해 생성된 고에너지 여기자 (exciton)가 낮은 에 너지 상태로 안정화될 때 방출되는 에너지를 빛으로 전환 하는 소자이다.

OLED 소자 구동 시 생성되는 여기자는 단일항 및 삼중항 상태로 각각 $25 \%, 75 \%$ 비율로 형성된다. 발광 소재는 이 두 여기자를 활용하는 메커니즘에 따라 형광 (fluorescence), 인광 (phosphorescence), 지연형광 (delayed fluorescence) 소재로 구분된다(Fig. 3). ${ }^{5)}$ 양자역학적으로 형광 소재의 경우 단일항 여기자 $\left(\mathrm{S}_{1}\right)$ 는 바닥상태 (ground state $\left(\mathrm{S}_{0}\right)$ ) 로 전이가 매우 높지만, 삼중항 여기자 $\left(\mathrm{T}_{1}\right)$ 는 $\mathrm{S}_{0}$ 로의 전 이가 비발광 과정인 발열과정으로 진행된다. 이로 인해 형광 소재는 $25 \%$ 의 에너지만 빛으로 전환되기 때문에 내 부 양자효율 (internal quantum efficiencies: IQE) 이 낮아 외부 양자효율 (External Quantum Efficiency: $\mathrm{EQE})$ 이 최대 5 7.5\%로 고효율의 OLED 제작이 어렵 다. 이러한 문제점을 해결하기 위해 1998년 미국 미시간 대학교 Forrest교수는 전이금속을 이용해 삼중항 여기자 를 함께 이용할 수 있는 기술을 개발하였다. 이 기술을 이 용한 인광소재는 전이금속에 의해 단일항 여기자가 빠르
고 효율적인 계간전이(Intersystem crossing; ISC)를 통 해 대부분 삼중항 상태로 전이된다. 또한 양자역학적으로 불가능한 $\mathrm{T}_{1}$ 에서 $\mathrm{S}_{0}$ 로의 전이가 전이금속에 의한 강한 spin-orbit coupling으로 인해 가능해져 $100 \%$ 내부양 자효율이 가능하다. 따라서 최대 20 30\%의 $\mathrm{EQE}$ 를 얻 을 수 있다. 현재까지 많은 연구를 통해 다양한 전이금속 을 이용한 인광소재가 개발되었다. 이들은 모든 가시광선 파장의 빛을 내고 양자효율이 높으며 수명 또한 우수하 다. 현재 녹색과 적색의 경우 OLED 디스플레이에 적용 됐다. 하지만 인광재료는 값 비싼 희토류 금속을 사용하 고 합성이 어려운 단점이 있다. 이러한 문제점을 해결하 고자 많은 연구가 이루어졌고, 2011년 큐슈대학교 Adachi는 전이금속을 사용하지 않는 순수한 유기물질 소 재로 삼중항 여기자를 이용할 수 있는 기술을 보고하였 다. ${ }^{6)}$ 이 물질은 삼중항으로 부터 단일항으로의 reverse intersystem crossing (RISC)을 이용하는 것으로 단일 항과 삼중항의 에너지 차이 $\left(\Delta \mathrm{E}_{\mathrm{ST}}\right)$ 가 작으면 $(\langle 0.5 \mathrm{eV})$ 상온에서 RISC가 가능해 삼중항으로 부터 단일항으로 에너지가 역전이 되고, 결과적으로 지연형광 $(\mathrm{TADF})$ 이 나오게 된다. 이러한 $\mathrm{TADF}$ 소재는 단일항과 삼중항 에 너지를 모두 이용하므로 인광 소재와 마찬가지로 $100 \%$ 내부양자효율이 가능하다. 인광 소재와 다른 점은 희토류 금속을 사용하지 않은 순수한 유기화합물이어서 가격 및

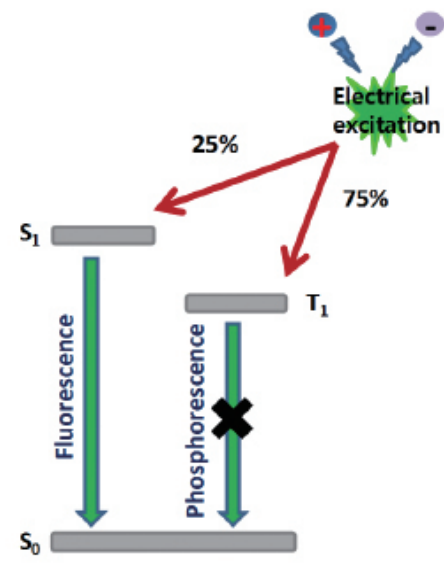

Fluorescent materials

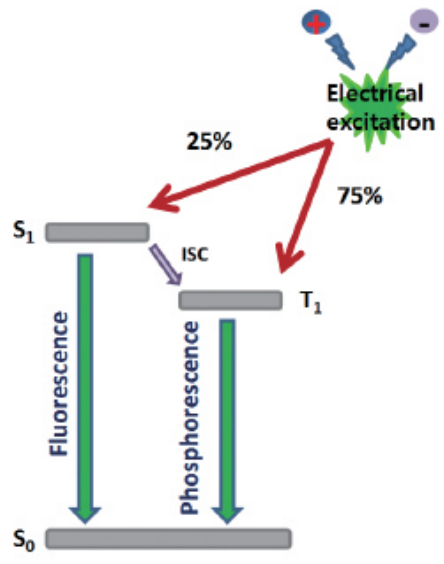

Phosphorescent materials

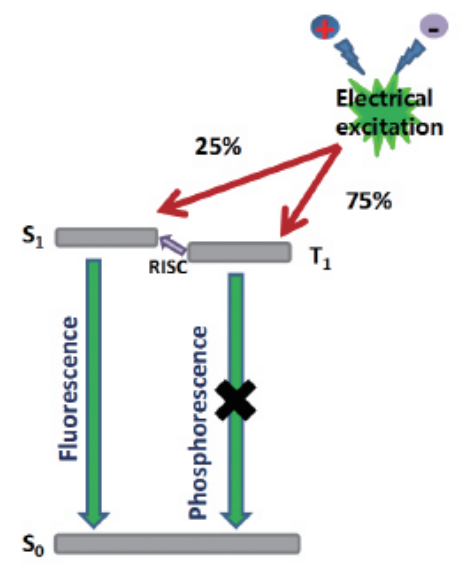

TADF materials

Fig. 3 형광, 인광, 지연형광 소재의 발광 메커니즘 비교 ${ }^{5}$ 

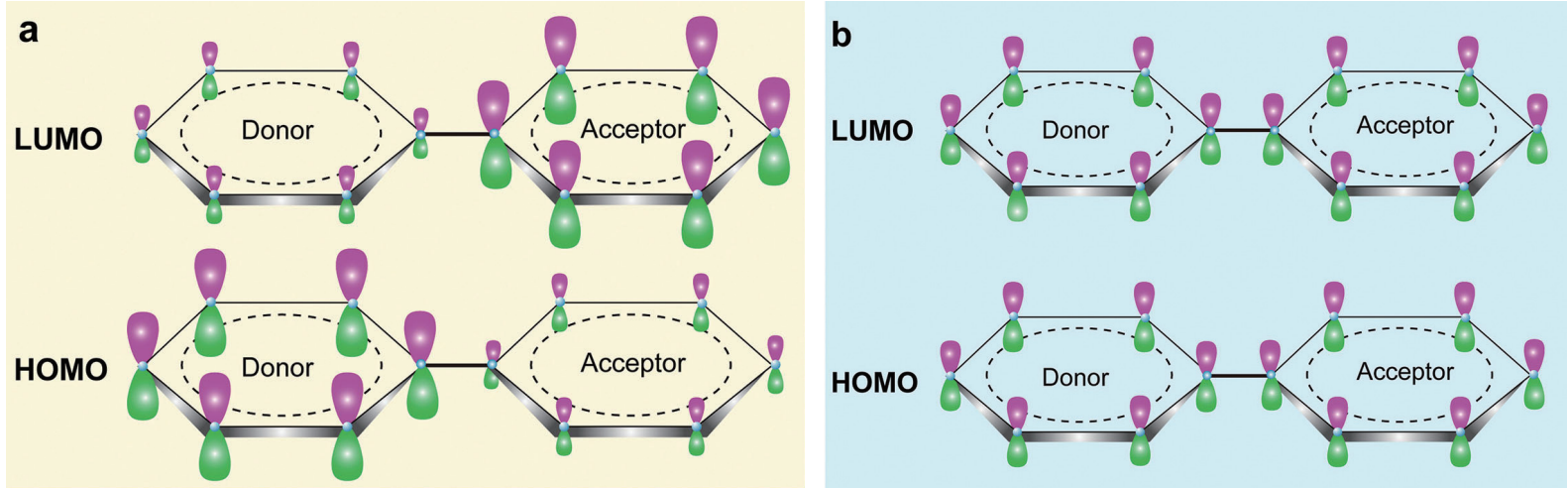

Fig. $4 \mathrm{HOMO}$ 와 LUMO 사이의 겹침이 적은 것(a)과 큰 것(b)의 도식ㄱ)

친환경 장점이 있고, 단일항을 이용해 발광을 하므로 인 광에서의 삼중항-삼중항 소멸로 인한 효율 감소를 크게 줄일 수 있다는 것이다.

\section{2 지연형광 재료의 분자 디자인 방법}

순수한 유기물질 $\mathrm{TADF}$ 소재는 전자주게 (Donor)와 전자받게 (Acceptor) 부분으로 이루어져 있어 분자내 전 하이동 (intra-molecular charge transfer: ICT) 특성 을 가지고 있다. 삼중항 에너지를 일중항으로 효율적으로 전이시키기 위해서는 일중항과 삼중항의 에너지 차이가 가능하면 작을수록 좋다. 분자 디자인 측면에서 볼 때 이 에너지 차이는 $\mathrm{HOMO}$ 와 LUMO가 입체적으로 얼마나 잘 분리되는지에 따라 달라진다. 잘 분리되면 에너지 차 이는 작지만, $\mathrm{HOMO}$ 와 LUMO가 작게 겹치면 FranckCondon 원칙에 따라 발광효율이 작아지는 문제점이 있 다. 그러므로 고효율 TADF 소재를 개발하기 위해서는 분자 디자인을 할 때 이러한 두 서로 상반된 점을 고려해 최적의 구조를 찾는 것이 매우 중요하다.

전자주게-전자받게 구조의 TADF 소재는 Fig. 5에서 와 같이 전자주게와 전자받게를 적당한 브릿지(bridge) 구조를 연결하여 얻을 수 있다. 여기서 HOMO와 LUMO 는 각각 전자주게와 전자받게 부분에 위치한다. 전자주게 는 주로 질소를 포함하는 carbazole, diphenyl amine, phenoxazine 등과 같은 구조이고, 강한 전자주게 (electron donating) 특성과 높은 삼중항 에너지를 갖고

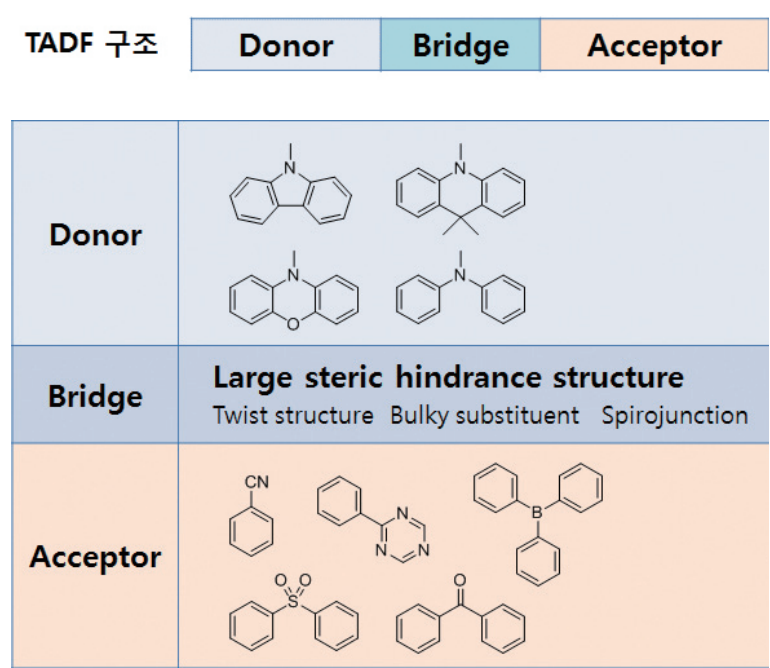

Fig. 5 D-A 형태의 TADF 소재 디자인 방법ㄱ)

있다. 전자받게는 다양한 구조가 가능하고 TADF 발광 특성, 색, 소자의 특성 조절에 중요하다. 공간적으로 이 두 부분이 분리된 분자에서 분자내 전하이동에 의해 발광 이 되나, 제한된 Frontier orbital 겹침으로 인해 일반적 으로 발광효율은 낮게 된다. 그러므로 고효율 TADF 소 재를 얻기 위해서는 $\mathrm{D}$ 와 $\mathrm{A}$ 의 구조뿐만 아니라, 전자주 게-전자받게 사이의 연결고리를 잘 선택해야 한다. $\mathrm{HOMO}$ 와 LUMO를 입체적으로 분리하는 방법은 전자주 게와 전자받게 사이에 큰 치환기 등을 도입해 입체장애를 주거나, spiro 구조 등을 이용해 $\pi-$ conjugation을 끓거 나, 공간적으로 두 부분을 분리하는 방법이 있다. 


\section{3 지연형광 재료의 개발 동향}

최초의 순수 유기물질 TADF 소재는 2011년 Adachi에 의해 개발된 PIC-TRZ이다(Fig. 6). 이 물질은 PLQY (photoluminescence quantum yield)가 $\mathrm{mCP}$ (1,3-bis (N-carbazolyl)benzene) 박막에서 $39 \%$ 정도였고, 이 물질을 사용한 소자의 $\mathrm{EQE}$ 도 5.3\%로 낮았다. ${ }^{6)}$ 이후 많 은 $\mathrm{TADF}$ 소재가 개발되었고, 대부분 효율이 유기금속 착체인 인광 소재와 동등한 수준을 보였다. 이러한 $\mathrm{TADF}$ 소재들을 대표적인 전자받게의 구조별로 개발 동향을 정 리했다.

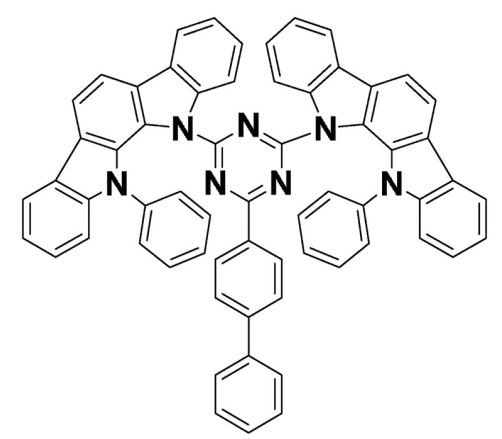

PIC-TRZ

Fig. $6 \mathrm{PIC}-\mathrm{TRZ}$ 의 분자 구조

\subsubsection{Cyano 기 기반 소재}

Cyano $(\mathrm{CN})$ 기는 전자를 당기는 특성이 강해 TADF 소재의 전자받게를 만들기에 좋다. $\mathrm{CN}$ 기를 가진 소재의 특징은 여기 상태의 비발광-비활성화(non-radiative deactivation)와 여기상태의 구조적 변화가 적어 PL 효 율이 크게 향상된다는 것이다. Spiro- $\mathrm{CN}$ 은 두 개의 $\mathrm{CN}$ 기를 가진 전자받게와 두 개의 $\mathrm{p}$-tolylamino 기를 가진 전자주게가 서로 spiro 구조로 연결되어 있는 소재다 (Fig. 7). 그래서 전자받게와 전자주게가 서로 입체장애 가 커 $\mathrm{HOMO}$ 와 LUMO가 잘 분리되어 있다. 이 물질은 $\triangle \mathrm{E}_{\mathrm{ST}}$ 가 $0.057 \mathrm{eV}$ 로 매우 작지만, PLQY가 $27 \%$ 로 낮아 $\mathrm{EQE}$ 도 $4.4 \%$ 로 낮았다. ${ }^{8}$ 이를 개선하기 위해 유사하게 Spiro 구조를 가진 Spiro-AC를 개발하였고, 이 물질은 $\Delta \mathrm{E}_{\mathrm{ST}}$ 가 $0.028 \mathrm{eV}$ 로 더 작고 PLQY도 $67.3 \%$ 로 높아
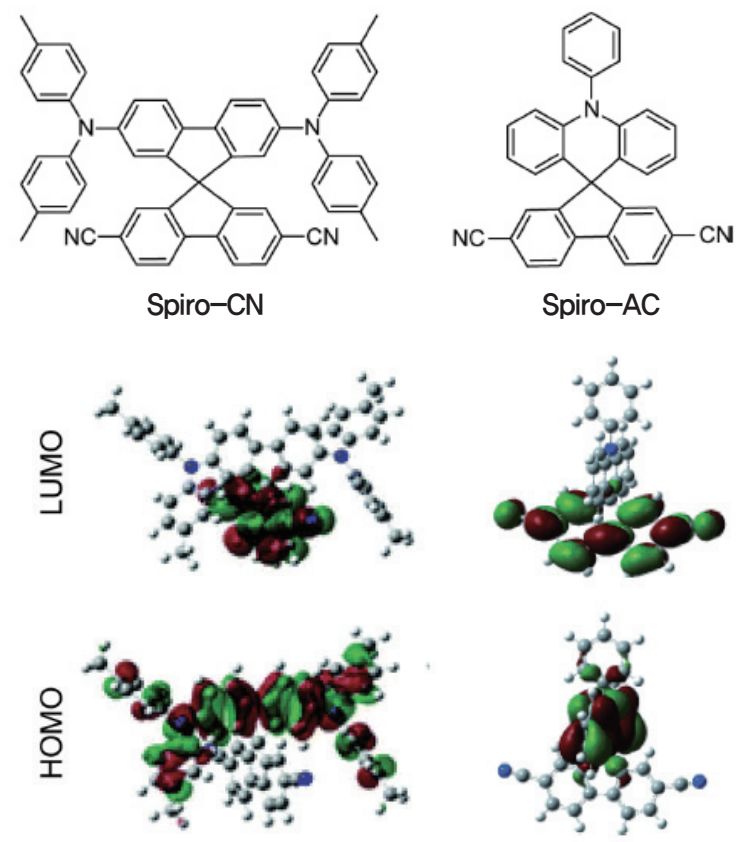

Fig. 7 Spiro-CN과 Spiro-AC의 분자 구조 및 LUMO/HOMO 분포8,9)

$\mathrm{EQE}$ 도 $10.1 \%$ 로 크게 향상되었다. ${ }^{9}$

이후 전자받게로는 동일한 Cyanobenzene을 사용하 였지만 전자주게를 이전과 달리 포화탄소를 통하지 않고 직접 전자받게에 연결하였다(Fig. 8). 전자주게로는 Carbazole을 사용하여 다양한 TADF 발광 소재를 만들

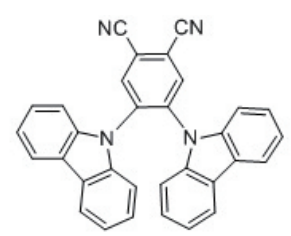

2CzPN
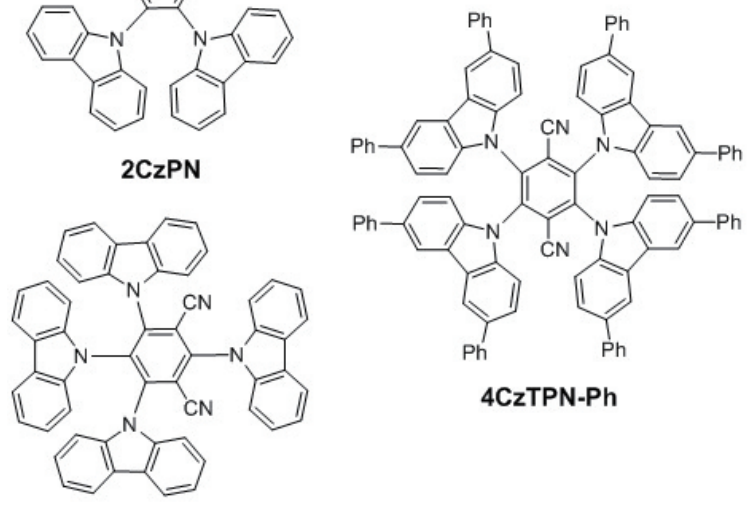

4CzIPN

Fig. 8 2CZPN, 4CZIPN, 4CZPTN-Ph의 분자 구조 


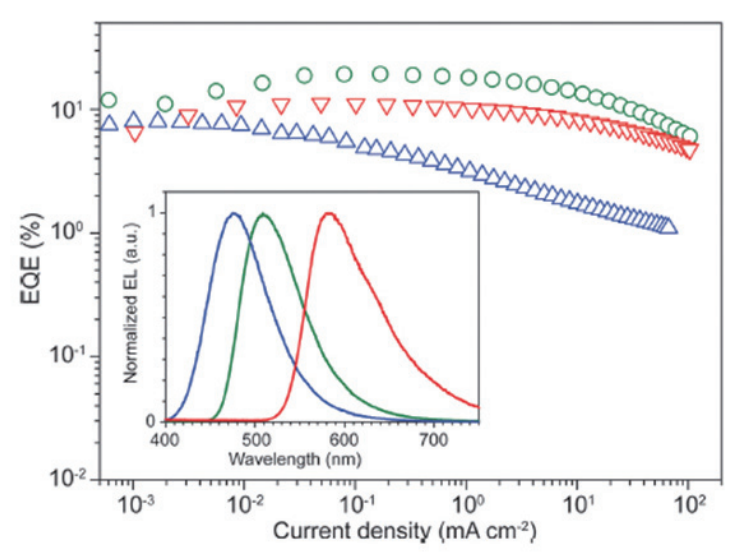

Fig. $92 \mathrm{CzPN}(\Delta), 4 \mathrm{Cz} \mathrm{PN}(0), 4 \mathrm{CzTPN}-\mathrm{Ph}(\nabla)$ 를 포함하는 OLED 의 효율 및 발광 색상 10$)$

었고 TADF 효율이 이전에 비해 크게 향상되었다. ${ }^{10)}$ $4 \mathrm{CzIPN}$ 의 경우는 PLQY가 $94 \%$ 로 아주 높았다. $\triangle \mathrm{E}_{\mathrm{ST}}$ 또한 Carbazole 기들이 dicyanobenzene 평면과 배향이 크게 달라 세 물질의 $\Delta \mathrm{E}_{\mathrm{ST}}$ 는 $0.083-0.15 \mathrm{eV}$ 로 비교적 작았다. 발광 소재의 발광 색상은 Carbazole의 수나 치 환기를 변경해 조절할 수 있었다. $2 \mathrm{CzPN}, 4 \mathrm{CzIPN}$, $4 \mathrm{CzTPN}-\mathrm{Ph}$ 의 색상은 각각 청색, 녹색, 오랜지색이었 다 (Fig. 9). 녹색인 $4 \mathrm{CzIPN}$ 의 경우 $\mathrm{EQE}$ 가 $19.3 \%$ 로 이 전에 비해 크게 향상되었다.

Biphenyl 기반의 두 물질, $\mathrm{CzBPCN}$ 와 $\mathrm{CNBPCz}$ 는 전 자주게의 위치에 따라 물질의 특성이 많이 다른데, Carbazole이 biphenyl의 ortho 위치에 있을 경우는 biphenyl의 회전장벽이 횔씬 커지는 "Donor interlock" 특성을 가진다. 따라서 $\mathrm{CzBPCN}$ 은 $\mathrm{CNBPCz}$ 에 비해 발 광 파장은 각각 $453 \mathrm{~nm}, 458 \mathrm{~nm}$ 로 거의 동일하지만, $\mathrm{EQE}$ 는 $14.0 \%, 4.8 \%$ 로 크게 다르고 반측 폭 또한 48 $\mathrm{nm}, 76 \mathrm{~nm}$ 로 크게 달랐다.
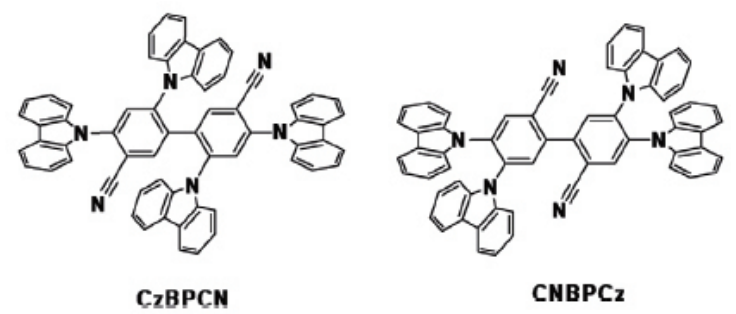

Fig. $10 \mathrm{CzBPCN}$ 과 $\mathrm{CNBPC}$ 의 분자 구조
전자주게인 carbazole의 수는 동일하나 일부 전자주게 의 구조를 달리하면 $\mathrm{TADF}$ 소재의 특성이 많이 달라진 다. 예를 들어 $3 \mathrm{Ph}_{2} \mathrm{CzCzBN}$ 의 경우 3 개의 $\mathrm{Ph}$ 가 치환된 carbazole과 1 개의 비치환 carbazole이 있는데, 4 개의 비치환 carbazole이 있는 $4 \mathrm{CzBN}$ 에 비해 $\triangle \mathrm{E}_{\mathrm{ST}}$ 는 작고 (0.19 vs $0.23 \mathrm{eV})$, PLQY는 훨씬 높다 (51 vs 91\%). ${ }^{12}$ 또 한, $3 \mathrm{Ph}_{2} \mathrm{CzCzBN}$ 의 Delayed lifetimes이 $5.2 \mu \mathrm{s}$ 로 $4 \mathrm{CzBN}(13.7 \mu \mathrm{s})$ 에 비해 짧아 고휘도에서의 효율저하 (roll-off)가 작고, 소자의 수명 ( $\mathrm{LT}_{90}$ : $90 \%$ of the initial luminance)이 40 배나 길었다. 이는 두 개의 다른 전자주게가 있을 경우 $3 \mathrm{LE}$ (high-lying localized triplet excited state)의 에너지를 낮추는데 효과적이고 3LE가 낮아지면 3CT (lowest charge transfer triplet excited state)와 혼합이 잘되어 RISC의 속도가 빨라지 기 때문이다. RISC 속도가 빨라지면 발광층 내에 삼중항 여기자가 줄어들어, 여기자의 소멸이 줄고 수명은 길어진 다. 결국 하늘색인 $3 \mathrm{Ph}_{2} \mathrm{CzCzBN}$ 의 $\mathrm{EQE}$ 는 $16.6 \%, \mathrm{LT}_{90}$ 는 38시간으로 우수한 특성을 보였다.

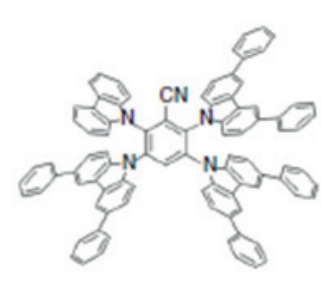

$3 \mathrm{Ph}_{2} \mathrm{CzCZBN}$

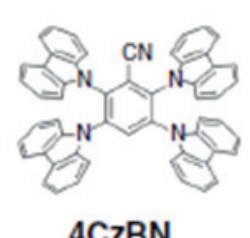

4CzBN
Fig. $113 \mathrm{Ph}_{2} \mathrm{CzC} z \mathrm{BN}$ 과 $4 \mathrm{Cz} \mathrm{BN}$ 의 분자 구조

\subsubsection{Triazine 기반 소재}

질소를 포함하는 방향족 고리 화합물은 질소의 전기음 성도가 탄소보다 크고 전자가 부족하여 전자받게로 사용 될 수 있다. 특히 질소가 세 개가 있는 Triazine (TRZ)의 경우 강한 전자받게 특성을 가지고 있어 $\mathrm{TADF}$ 소재 개 발에 많이 사용되었다. DIC-TRZ의 경우 이전의 PICTRZ보다 전자주게와 전자받게간의 입체장애가 더 큰 구 조를 갖고 있어 $\mathrm{TADF}$ 특성이 좋아졌다. 결과적으로 $\mathrm{EQE}$ 가 $11.7 \%$ 로 PIC-TRZ (5.3\%)보다 효율이 크게 향 
상되었다 (Fig. 12). ${ }^{13)} \mathrm{PIC}-\mathrm{TRZ} 2$ 의 경우는 입체 장애가 더 커져서 $\Delta \mathrm{E}_{\mathrm{ST}}$ 가 $0.02 \mathrm{eV}$ 로 아주 작아 $\mathrm{EQE}$ 가 $14 \%$ 로 더욱 개선되었다. ${ }^{14)}$

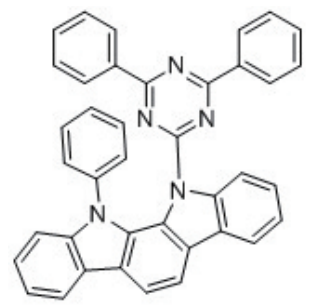

DIC-TRZ

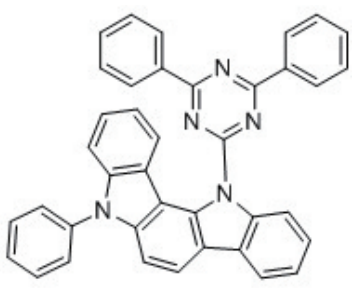

PIC-TRZ2
Fig. 12 DIC-TRZ와 PIC-TRZ2의 분자 구조

$\mathrm{BCzT}$ 는 위의 구조와 유사한 $\mathrm{CzT}$ 와 달리 전자주게와 전자받게 사이에 phenyl 고리가 연결되어 있는데, 이 연 결고리가 있으면 바닥상태와 일중항 여기상태의 전자파 동함수의 겹침밀도가 증가해 발광 속도 상수 (radiative rate constant)가 커진다. 비록 phenyl 고리가 있으면 $\triangle \mathrm{E}_{\mathrm{ST}}$ 는 더 커지지만 이 효과로 인해 비슷한 발광파장을 가진 $\mathrm{BCzT}$ 는 $\mathrm{CzT}$ 보다 PLQY와 $\mathrm{EQE}$ 가 훨씬 높았다 (PLQY: 96 vs 40, EQE: 20\% vs 4\%). ${ }^{15}$

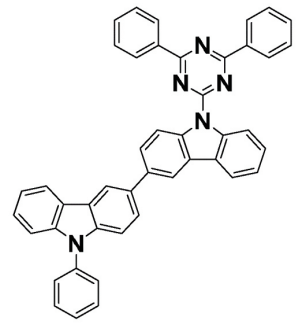

CzT

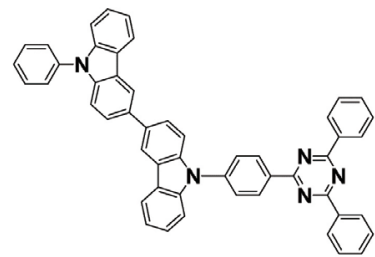

$\mathrm{BCzT}$
Fig. $13 \mathrm{CzT}$ 와 $\mathrm{BCz}$ 의 분자 구조

DPA-TRZ와 DACT-II는 구조적으로 phenyl 연결고 리와 연결된 전자주게가 서로 다르다. DPA-TRZ는 비발 광 쇠태 (decay)가 박막에서 완전히 억제되어 PLQY가 $100 \%$ 로 높은데, 이것은 전자주게와 전자받게 사이의 괘
도 겹침이 더 좋아 전이 쌍극자 모멘트가 더 강해져 발광 속도 상수가 증가하기 때문이다. 이 물질을 이용한 소자 의 $\mathrm{EQE}$ 는 $13.8 \%$ 로 녹색발광을 냈다. ${ }^{16)} \mathrm{DACT}-\mathrm{II}$ 는 $\mathrm{DPA}-\mathrm{TRZ}$ 와 마찬가지로 PLQY가 $100 \%$ 로 동일했으나, DACT-II의 $\Delta \mathrm{E}_{\mathrm{ST}}$ 는 $0.01 \mathrm{eV}$ 로 DPA-TRZ $(0.11 \mathrm{eV})$ 보 다 훨씬 작아서 $\mathrm{RISC}$ 효율이 높아 $\mathrm{EQE}$ 가 $29.6 \%$ 로 훨씬 높았다 (발광 파장은 비슷). ${ }^{17)} \mathrm{DACT}-\mathrm{II}$ 의 우수한 발광특 성은 carbazole과 phenyl 연결고리와의 dihedral angle $(\alpha)$ 의 조절의 결과인데, 이 각도를 조절하면 oscillator strength (f) (발광 속도 상수를 증가시킴)와 $\Delta \mathrm{E}_{\mathrm{ST}}$ 를 최 적화할 수 있어서 PLQY (f와 관련됨)와 RISC $\left(\triangle \mathrm{E}_{\mathrm{ST}}\right.$ 와 관련됨)를 최적화할 수 있다.
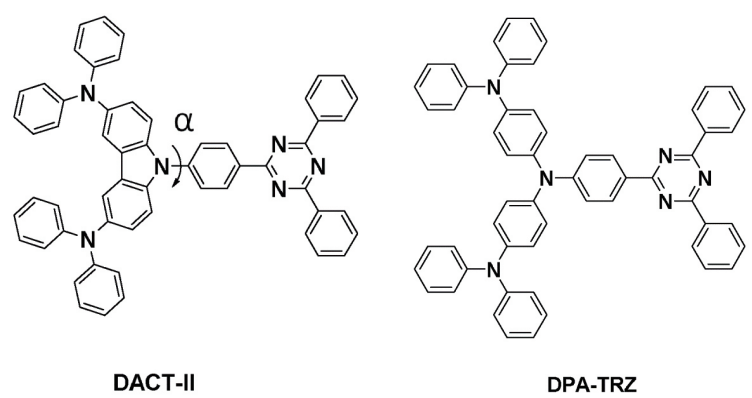

Fig. 14 DACT-\|와 DPA-TRZ의 분자 구조

\subsection{3보론 기반 소재}

보론 원자는 빈 $\mathrm{p}$ 오비탈을 가지고 있어 $\mathrm{p}_{z}-\pi$ conjugation 을 통해 강한 전자받게로 사용될 수 있다. 보론 전자받게 기 반의 다양한 $\mathrm{TADF}$ 소재 (Fig. 15)가 개발되었다. 한 예로 고 리구조의 보론 전자받게를 사용한 DMAC-PXB는 PLQY가 $98 \%$ 로 대단히 높고 $\Delta \mathrm{E}_{\mathrm{ST}}$ 가 $0.03 \mathrm{eV}$ 로 아주 작았다. 결과 적으로 이 물질을 사용한 청색 소자의 $\mathrm{EQE}$ 는 $15.1 \%$ 로 비교 적 높았다. ${ }^{18)}$ 비고리 구조의 보론 전자받게를 사용한 PXZ$\mathrm{MeS}_{3} \mathrm{~B}$ 의 경우도 PLQY가 $92 \%$ 로 대단히 높고 $\triangle \mathrm{E}_{\mathrm{ST}}$ 가 0.07 $\mathrm{eV}$ 로 작았고 $\mathrm{EQE}$ 는 $22.8 \%$ 로 이 물질 또한 우수한 $\mathrm{TADF}$ 특성을 보였다. ${ }^{19}$ 다른 예로 DMAC-PXB와 같이 고리형 보 론 전자받게를 사용하고 전자주게를 다른 위치에 도입한 $\mathrm{ACRPOB}$ 는 $\mathrm{PLQY}$ 가 $100 \%$ 이고 청색이면서 $\mathrm{EQE}$ 도 


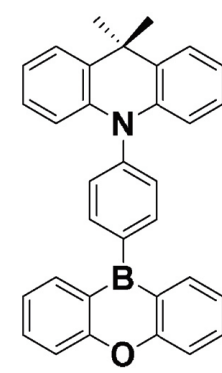

DMAC-PXB

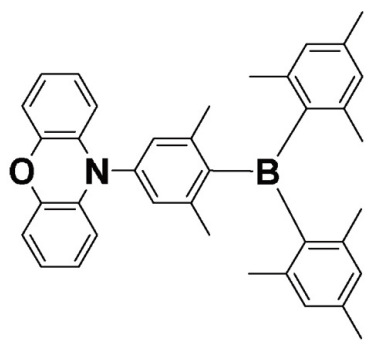

PXZ-Mes $_{3} \mathrm{~B}$

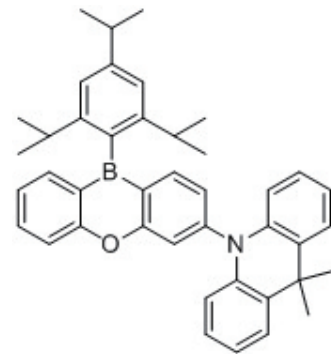

ACRPOB

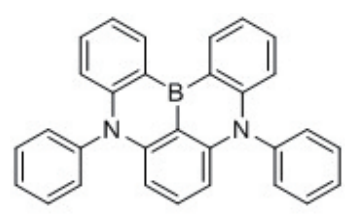

DABNA-1

Fig. 15 DMAC-PXB, PXZ-Mes ${ }_{3} B, A C R P O B$ 와 DABNA-1의 분자 구조

$21.7 \%$ 로 아주 높았다. ${ }^{20)}$ 또 다른 독특한 구조의 DABNA -1 은 다중 공명구조를 가지고 있는데 $\mathrm{LUMO}$ 는 보론과 보론의 ortho, para 위치의 탄소에 있고, $\mathrm{HOMO}$ 는 질소 와 보론의 meta 위치의 탄소에 있다. 이러한 다중 공명 효과를 이용한 소재의 경우 일반적인 TADF 소재의 문제 점인 넓은 발광 스펙트럼의 반측 폭이 크게 좁아진다는 점이다. $\mathrm{DABNA}-1$ 또한 PLQY가 $88 \%$ 로 높고 진청색 소 재이다. ${ }^{21}$

위에서 본 바와 같이 보론 기반의 $\mathrm{TADF}$ 소재는 일반 적으로 보론 원자에 의한 $\mathrm{LUMO}$ 의 강한 지역편재 (localization) 효과 때문에 $\Delta \mathrm{E}_{\mathrm{ST}}$ 가 작고 일반적으로 PLQY가 88 100\%로 매우 높다. 또한 DABNA 시리즈는 반측 폭이 아주 좁은 빛을 내기 때문에 발광 소재로써 아 주 흥미로운 물질이다.

최근에는 새로운 구조의 전자받게를 도입한 $\mathrm{TADF}$ 특 성이 아주 뛰어난 두 소재가 개발되었다. $\mathrm{CzDBA}$ 는 9,10-dihydro-9,10-diboraanthracene (DBA) 기반의 소재로 보론 원자 두 개와 전자주게 두 개로 이루어진 물 질로 PLQY가 $\sim 100 \%$, 이중(쌍)극자배열 (dipole orientation)이 $84 \%$ 로 높아서, 이 녹색 소재의 $\mathrm{EQE}$ 는 $37.8 \%$ 로 대단히 높고 roll-off도 아주 낮았다. ${ }^{22)}$ 또 다른 소재인 $\mathrm{TDBA}-\mathrm{DI}$ 는 대칭적이고 rigid한 bicyclic 보론 전자받게를 사용하고 전자주게로는 Diindolocarbazole 을 도입한 것이 특징적인데, 이 물질은 청색이면서도 $\mathrm{PLQY}$ 가 99\%, EQE가 38.15\%로 아주 뛰어난 TADF 특 성을 보였다. 이렇게 높은 효율은 $\mathrm{CzDBA}$ 와 마찬가지로

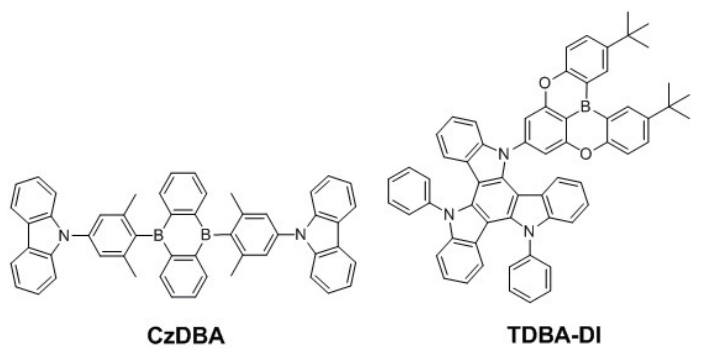

Fig. 16 CzDBA와 TDBA-DI의 분자 구조

높은 PLQY, 이중(쌍)극자배열, 그리고 빠른 RISC때문 이다. ${ }^{23)}$

\subsubsection{Diphenyl sulfone 기반 소재}

Diphenyl sulfone은 전자를 강하게 받는 특성을 가지 고 있고 중앙이 꺽이는 구조를 갖고 있어 청색 $\mathrm{TADF}$ 소 재를 개발하는데 유리하다. Diphenyl sulfone 기를 전자 받게로 사용하고 5-phenyl-5,10-dihydrophenazine, phenoxazine, 9,9-dimethyl-9,10-dihydroacridine 와 같이 서로 다른 전자주게를 사용하여 $\mathrm{TADF}$ 특성을 비 교해 본 결과 $\Delta \mathrm{E}_{\mathrm{ST}}$ 는 모두 $0.08 \mathrm{eV}$ 이었고 $\mathrm{PL}$ 파장은 각 각 $577 \mathrm{~nm}, 507 \mathrm{~nm}, 460 \mathrm{~nm}$ 였으며 PLQY는 3, 80, $80 \%$ 로 Donor의 구조에 따라 특성이 다르게 나타났다 (Fig. 17). ${ }^{24)}$ 이들 중에 $\mathrm{DMAC}-\mathrm{DPS}$ 는 $\mathrm{CIE}$ 색좌표가 $(0.16,0.20)$ 로 청색이면서 $\mathrm{EQE}$ 가 $19.5 \%$ 로 금속을 사용 하지 않은 순수 유기물질이면서 청색재료로는 최초로 가 장 높은 효율을 보였다. 또한 고휘도 $(1000 \mathrm{~cd} / \mathrm{m} 2)$ 도 $\mathrm{EQE}$ 가 $16 \%$ 로 높게 유지가 되었다. 


\section{특 집 ㅁㅃ 이주영}

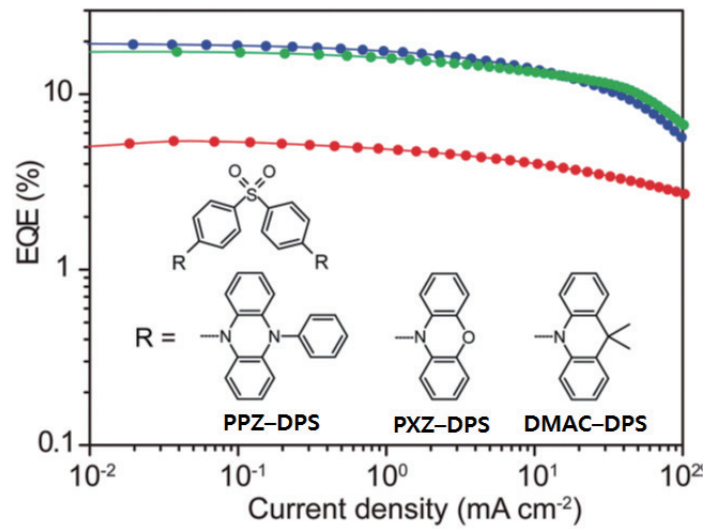

Fig. $17 \mathrm{PPZ}-\mathrm{DPS}(\bullet), \mathrm{PXZ}-\mathrm{DPS}(\bullet)$, DMAC-DPS(•)의 분자 구조 및 OLED 효율 24)

이후 Diphenyl sulfone 구조를 고리화하여 개선된 $\mathrm{TADF}$ 특성을 보이는 물질 두 가지가 보고되었다. $\mathrm{DDMA}-$ TXO2는 DMAC-DPS의 diphenyl sulfone acceptor 구조 를 고리화한 물질로 색 순도 $(465 \mathrm{~nm})$ 가 DMAC-DPS $(480 \mathrm{~nm})$ 보다 개선되었고, $\mathrm{EQE}(22.4 \%)$ 도 향상되었 다. ${ }^{25)} \mathrm{Ac}-\mathrm{OSO}$ 도 $\mathrm{DDMA}-\mathrm{TXO} 2$ 와 동일한 Acceptor를 갖 고 있으나 Donor를 하나만 넣은 물질로 DDMA-TXO2와 마찬가지로 $\mathrm{EQE}(20.5 \%)$ 가 향상되었다. ${ }^{26)}$

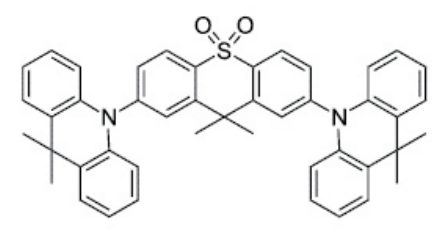

DDMA-TX02

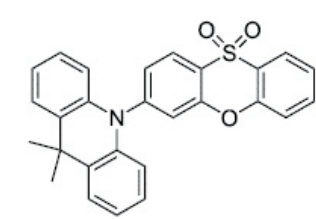

Ac-0SO
Fig. $18 \mathrm{DDMA}-\mathrm{TXO} 2$ 와 $\mathrm{Ac}-\mathrm{OSO}$ 의 분자 구조

\subsubsection{Diphenyl ketone 기반 소재}

Diphenyl ketone은 카르보닐기의 전자를 강하게 받는 특성으로 $\mathrm{TADF}$ 소재의 전자받게로 사용이 되었다. Fig. 19는 Diphenyl ketone과 전자주게로 Carbazole 또는 Phenoxazine을 도입하여 만든 다양한 TADF 소재를 보 여 준다. ${ }^{27)}$ 전자받게 및 전자주게의 구조에 따라 색상을 조절할 수가 있었고 $\mathrm{TADF}$ 특성이 다르게 나타났다.
Carbazole일 경우는 PL 파장이 $444 \mathrm{~nm}$ 로 청색이고, Phenoxazine의 경우는 Ketone 기의 수에 따라 색상이 다르게 나타났다. 한 개일 때는 $538 \mathrm{~nm}$, 두 개일 때는 conjugation 길이가 길어져 $555 \mathrm{~nm}$ 였다. PLQY와 EQE 는 각각 $55,70,36 \%$ 와 8.1, 10.7, 4.2\%로 구조에 따라 다르게 나타났다.

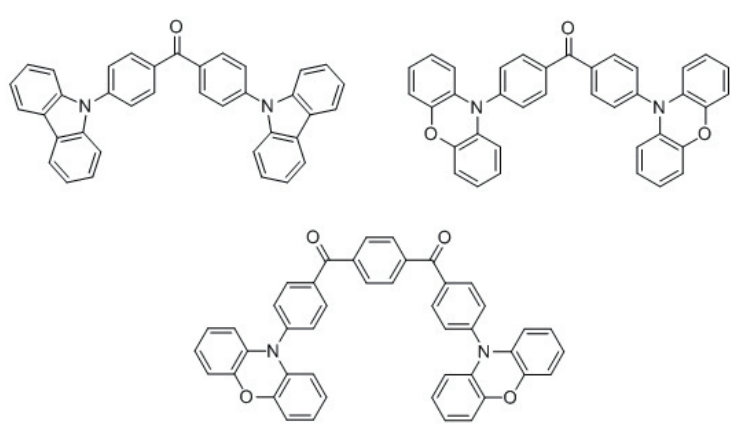

Fig. 19 Diphenyl ketone 기를 도입한 TADF 소재

Spiro-junction을 도입한 예 (Fig. 20)로 ACRSA는 $\mathrm{HOMO}$ 와 LUMO가 효과적으로 분리되어 PLQY는 $81 \%$, $\mathrm{EQE}$ 는 $16.5 \%$ 로 비교적 우수한 $\mathrm{TADF}$ 특성을 보였다 $\left(\lambda_{\max }: \approx 500 \mathrm{~nm}\right){ }^{28)}$ Carbonyl기가 추가로 고리구조로 도입된 Anthraquinone 기반의 2,6-Bis[4(diphenylamino)phenyl]anthraquinone (b1)는 붉은색 소재이다. 붉은색 $\mathrm{TADF}$ 소재의 경우 fluorescence rate $\left(\mathrm{k}_{\mathrm{F}}\right)$ 가 크고 일중항과 삼중항의 에너지 차이가 작아야 하 는데, 분자내 전하 이동 물질의 경우에는 전자주게와 전 자받게 사이의 거리를 멀리하면 이 두 가지가 모두 충족 된다는 것이 이 물질에 의해 밝혀졌다. 이 물질의 PLQY 는 $80 \%, \mathrm{EQE}$ 는 $12.5 \%$ 로 이 당시에는 가장 우수한 붉은 색 $\mathrm{TADF}$ 소재였다 $\left(\lambda_{\max }: 624 \mathrm{~nm}\right){ }^{29)} \mathrm{DTCBPy}$ 는 Benzoylpyridine 전자받게를 사용한 소재로 전하이동이 전자주게와 전자받게 사이에 분자를 통해서 일어나는 것 이 아니라 공간적으로 일어난다는 점이 특징이다. 이 물 질의 PLQY는 $91 \%, \mathrm{EQE}$ 는 $27.2 \%$ 로 대단히 우수했다 $\left(\lambda_{\max }: 518 \mathrm{~nm}\right){ }^{30)}$ 


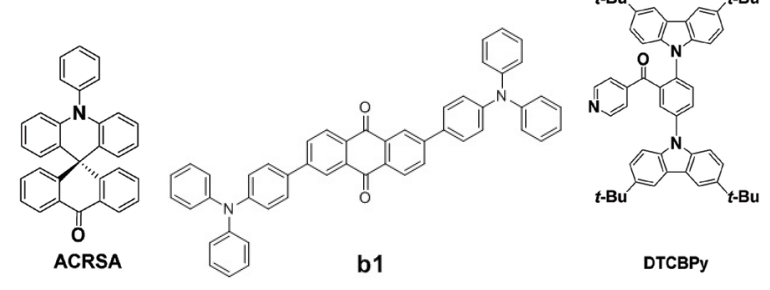

Fig. $20 \mathrm{ACRSA}$, b1와 DTCBPy의 분자 구조

\section{3. 결론}

짧은 기간 동안에 다양한 구조의 $\mathrm{TADF}$ 소재가 개발되 었고, 본 기고에서는 이들 중 구조적으로 특징을 갖는 물 질들을 중심으로 살펴 보았다. 초기 물질들은 $\mathrm{TADF}$ 특 성이 낮았지만, 이후 다양한 분자 디자인 기술이 개발되 어 현재 상용화된 인광소재와 동등 이상의 특성을 보이는 여러 TADF 소재가 개발되었다. 하지만 이것은 TADF 소 자의 효율 측면이고 아직 해결해야 할 문제점이 남아 있 다. 일반적으로 $\mathrm{TADF}$ 소재는 분자 내 전하이동에 의해 발광을 하므로 발광 스펙트럼의 반측 폭이 넓어 색 순도 가 떨어진다. 이 문제를 해결하기 위해서는 DABNA 시 리즈와 같은 독특한 분자 디자인 전략의 개발이 필요하 다. 또한 대부분의 $\mathrm{TADF}$ 소재는 여기자의 수명이 길어 여기자들이 서로 반응하여 소멸되는 현상이 심한데, 특히 고휘도에서의 효율저하가 심하다. 위에서 살펴 본 바와 같이 일부 물질에서 이 문제가 많이 향상되었으나 더욱 개선할 필요가 있다. 끝으로 $\mathrm{TADF}$ 소재의 상용화를 위 해서 무엇보다 시급히 해결해야 할 문제는 짧은 수명이 다. 지금까지의 연구는 대부분 효율향상에 집중되었고 다 양한 분자 디자인 기술의 개발로 많은 발전을 이루었다. 하지만 수명에 대한 연구는 아직 별로 이루어지지 않았 다. 따라서 $\mathrm{TADF}$ 소재의 상용화를 위해서는 향후 연구 는 TADF 소재의 수명 연장에 집중할 필요가 있다.

\section{참고문헌}

1. W. K. Bae, K. Char, H. Hur, and S. Lee, "Single-Step Synthesis of Quantum Dots with Chemical Composition Gradients" Chem. Mater, 20 [2] 531-39 (2008).
2. N. K. Kumawat, D. Gupta, and D. Kabra, "Recent Advances in Metal Halide-Based Perovskite LightEmitting Diodes” Energy Technol., 5, 1734 - 1749 (2017)

3. C. Bizzarri, F. Hundemer, J. Busch, and S. Bräse, "Triplet emitters versus TADF emitters in OLEDs: A comparative study" Polyhedron, 140, 51-66 (2018)

4. K. Matsuo, and T. Yasuda, 'Boronate- and borinatebased $\mathrm{p}$-systems for blue thermally activated delayed fluorescence materials", Chem. Commun., 55, 25012504 (2019)

5. Michael Y. Wong, Eli Zysman-Colman, "Recent advances on organic blue thermally activated delayed fluorescence (TADF) emitters for organic lightemitting diodes (OLEDs)", Beilstein J. Org. Chem., 14, $282-308$ (2018)

6. A. Endo, K. Sato, K. Yoshimura, T. Kai, A. Kawada, H. Miyazaki, and C. Adachi, "Efficient up-conversion of triplet excitons into a singlet state and its application for organic light emitting diodes” Appl. Phys. Lett., 98 [8] 083302 (2011)

7. Ye Tao, Kai Yuan, Ting Chen, Peng Xu , Huanhuan Li, Runfeng Chen, Chao Zheng, Lei Zhang, and Wei Huang, "Thermally Activated Delayed Fluorescence Materials Towards the Breakthrough of Organoelectronics", Adv. Mater., 26(47), 7931-7958 (2014)

8. T. Nakagawa, S. Y. Ku, K. T. Wong, and C. Adachi, "Electroluminescence based on thermally activated delayed fluorescence generated by a spirobifluorene donor-acceptor structure", Chem. Commun., 48, 9580 (2012)

9. G. Mehes, H. Nomura, Q. S. Zhang, T. Nakagawa, and C. Adachi, "Enhanced electroluminescence efficiency in a spiro-acridine derivative through thermally activated delayed fluorescence", Angew. Chem. Int. Edit, 51, 11311 (2012)

10 H. Uoyama, K. Goushi, K. Shizu, H. Nomura, and C. Adachi, "Highly efficient organic light-emitting diodes from delayed fluorescence", Nature, 492, 234 (2012)

11. Y. J. Cho, S. K. Jeon, S. -S. Lee, E. Yu, and J. Y. Lee, "Donor Interlocked Molecular Design for Fluorescencelike Narrow Emission in Deep Blue Thermally Activated Delayed Fluorescent Emitters" Chem. Mater., 28, 5400 (2016)

12. C.-Y. Chan, M. Tanaka, H. Nakanotani, and C. Adachi, "Efficient and stable sky-blue delayed 
CERAMIST

특 집 ㅁㅃ 이주영

fluorescence organic light-emitting diodes with ClEy below 0.4" Nat. Commun., 9, 5036 (2018)

13. D. Zhang, L. Duan, C. Li, Y. Li, H. Li, D. Zhang, and Y. Qiu, "High-Efficiency Fluorescent Organic LightEmitting Devices Using Sensitizing Hosts with a Small Singlet-Triplet Exchange Energy" Adv. Mater., 26, 5050 (2014)

14. K. Sato, K. Shizu, K. Yoshimura, A. Kawada, H. Miyazaki, and C. Adachi, "Organic Luminescent Molecule with Energetically Equivalent Singlet and Triplet Excited States for Organic Light-Emitting Diodes" Phys. Rev. Lett., 110, 247401 (2013)

15. K. Shizu, H. Noda, H. Tanaka, M. Taneda, M. Uejima, T. Sato, K. Tanaka, H. Kaji, and C. Adachi, "Highly Efficient Blue Electroluminescence Using Delayed-Fluorescence Emitters with Large Overlap Density between Luminescent and Ground States" J. Phys. Chem. C, 119, 26283 (2015)

16. K. Shizu, M. Uejima, H. Nomura, T. Sato, K. Tanaka, H. Kaji, andC. Adachi, "EnhancedElectroluminescence from a Thermally Activated Delayed-Fluorescence Emitter by Suppressing Nonradiative Decay" Phys. Rev. Appl., 3, 014001 (2015)

17. H. Kaji, H. Suzuki, T. Fukushima, K. Shizu, K. Suzuki, S. Kubo, T. Komino, H. Oiwa, F. Suzuki, A. Wakamiya, Y. Murata, and C. Adachi, "Purely organic electroluminescent material realizing $100 \%$ conversion from electricity to light" Nat. Commun, 6, 8476 (2015)

18. Y. Kitamoto, T. Namikawa, D. Ikemizu, Y. Miyata, T. Suzuki, H. Kita, T. Sato, and S. Oi, "Light blue and green thermally activated delayed fluorescence from 10H-phenoxaborin-derivatives and their application to organic light-emitting diodes" J. Mater. Chem. C, 3, $9122(2015)$

19. K. Suzuki, S. Kubo, K. Shizu, T. Fukushima, A. Wakamiya, Y. Murata, C. Adachi, and H. Kaji, "Triarylboron-Based Fluorescent Organic LightEmitting Diodes with External Quantum Efficiencies Exceeding 20" Angew. Chem., Int. Ed. Engl., 54, 15231 (2015)

20. M. Numata, T. Yasuda, and C. Adachi, "High efficiency pure blue thermally activated delayed fluorescence molecules having $10 \mathrm{H}$-phenoxaborin and acridan units" Chem. Commun., 51, 9443 (2015)

21. T. Hatakeyama, K. Shiren, K. Nakajima, S. Nomura, S. Nakatsuka, K. Kinoshita, J. Ni, Y. Ono, and T. Ikuta, "Ultrapure Blue Thermally Activated Delayed
Fluorescence Molecules: Efficient HOMO-LUMO Separation by the Multiple Resonance Effect" $A d v$. Mater., 28, 2777 (2016)

22. T.-L. Wu, M.-J. Huang, C.-C. Lin, P.-Y. Huang, T.-Y. Chou, R.-W. C.-Cheng, H.-W. Lin, R.-S. $\mathrm{Liu}$, and C. $-\mathrm{H}$. Cheng, "Diboron compound-based organic light-emitting diodes with high efficiency and reduced efficiency roll-off" Nature Photonics, 12, $235-240$ (2018)

23. D. H. Ahn, S. W. Kim, H. Lee, I. J. Ko, D. Karthik, J. Y. Lee, and J. H. Kwon, "Highly efficient blue thermally activated delayed fluorescence emitters based on symmetrical and rigid oxygen-bridged boron acceptors" Nature Photonics, 13, 540-546 (2019)

24. Q. Zhang, B. Li, S. Huang, H. Nomura, H. Tanaka, and C. Adachi, "Efficient blue organic light-emitting diodes employing thermally activated delayed fluorescence" Nat. Photon. , 8, 326 (2014)

25. P. L. dos Santos, J. S. Ward, M. R. Bryce, and A. P. Monkman, "Using Guest-Host Interactions To Optimize the Efficiency of TADF OLEDs" J. Phys. Chem. Lett., 7, 3341-3346 (2016)

26. S. Y. Lee, C. Adachi, and T. Yasuda, "High-Efficiency Blue Organic Light-Emitting Diodes Based on Thermally Activated Delayed Fluorescence from Phenoxaphosphine and Phenoxathiin Derivatives" Adv. Mater, 28, 4626-4631 (2016)

27. S. Y. Lee, T. Yasuda, Y. S. Yang, Q. Zhang, and C. Adachi, "Luminous butterflies: efficient exciton harvesting by benzophenone derivatives for fullcolor delayed fluorescence OLEDs" Angew. Chem. Int. Edit., 53, 6402 (2014)

28. K. Nasu, T. Nakagawa, H. Nomura, C. J. Lin, C. H. Cheng, M. R. Tseng, T. Yasuda, and C. Adachi, "A highly luminescent spiro-anthracenone-based organic light-emitting diode exhibiting thermally activated delayed fluorescence" Chem. Commun., 49, 10385 (2013).

29. Q. Zhang, H. Kuwabara, W. J. Potscavage, S. Huang, Y. Hatae, T. Shibata, and C. Adachi, "AnthraquinoneBased Intramolecular Charge-Transfer Compounds: Computational Molecular Design, Thermally Activated Delayed Fluorescence, and Highly Efficient Red Electroluminescence" J. Am. Chem. Soc., 136, 18070 (2014)

30. P. Rajamalli, N. Senthilkumar, P. Gandeepan, P. Y. 
Huang, M. J. Huang, C. Z. Ren-Wu, C. Y. Yang, M. J. Chiu, L. K. Chu, H. W. Lin, and C. H. Cheng, "A New Molecular Design Based on Thermally Activated Delayed Fluorescence for Highly Efficient Organic Light Emitting Diodes" J. Am. Chem. Soc., 138, 628 (2016)

\section{이이 주 영}

(1) 1995년 포항공과대학교 화학과 박사

1996년 영국 Birmingham University 화학과 박사후 연구원

( 2014년 SK케미칼 생명과학연구소 수석 연구원

( 2) 2014년 현재 경희대학교 정보디스플레이학과 학술연구교수 